\title{
Reflections and Explorations on the Mode of Diversion under the Major Enrollment Policy-Take North China Electric Power University as an example
}

\author{
Huiwen Gao ${ }^{1}$, Mengyao Fu ${ }^{1}$, Ruifeng Qian ${ }^{1}$ \\ ${ }^{1}$ North China Electric Power University, 2 Beinong Road, Huilongguan Town, Changping District, Beijing,
} China

Keywords: major enrollment policy; professional diversion mode; key influencing factors, time preference

\begin{abstract}
With the method of self-compiling questionnaire, the time preference of students ' professional diversion and the influencing factors of professional selection are investigated. The results showed that: (1) The time preference of professional diversion for the majority of students in the semester is in the second term of the first grade. (2) The own interests, individual abilities, professional employment prospects and disciplinary strength are the key factors that affected students ' professional diversion. According to the investigation results, this paper gives a brief view on the present situation of specialty diversion in colleges and universities, sums up the influential factors in the process of professional diversion, and provides theoretical guidance for students ' professional choice and the development of diversion programs. On the basis of investigation and analysis, this paper probes into the new ideas of the professional diversion mode, and puts forward the diversion rules for reference to the colleges and universities with professional characteristics
\end{abstract}

\section{Introduction}

In the past few decades, our country in the talent training and enrollment policy on the continuous exploration, reform, from the beginning of the founding of the Soviet Union to learn the talent training model for professional training ideas, and gradually changed into a "big class enrollment, triage training" training ideas. This is closely related to the development of society and the growing demand of "all-round talents". Along with the "national medium and long-term education reform and development planning outline (2010-2020)", the University personnel training mode and talent training quality problems are constantly pushed to the forefront of the times. Nowadays, there are not many researches on the cultivation of large enrollment talents, and the research on talent training has mainly focused on the training of talents, the present situation, the development countermeasures and the training mode. How to shunt the talent under the policy of large enrollment, the design and implementation of concrete diversion mode are paid more and more attention.

\section{Research Background}

The background of major categories of enrollment under the policy of professional diversion refers to the admission phase of the close to the major disciplines by the merger. Students enter the corresponding subject of major classes of study, in the completion of 1-2 years of general education, according to achievements, interests and volunteering and other factors subdivided into the professional training stage. This kind of student's admission mode avoids the blindness of students ' professional choice, and is helpful for students to choose more suitable professional types after they have a certain understanding of their majors. Nowadays, many famous universities both national and abroad adopt the mode of professional diversion in the later stage of enrollment. North China Electric Power University is a competitive college, which not only was honored with "211 project" and "985 engineering advantage Subject Innovation platform". But also a special advantage of the power of colleges and universities. With the release of the Ministry of Education's guidance on promoting the formation of the linkage mechanism of employment and enrollment planning in 
colleges and universities, NCEPU has also begun the reform of major enrollment policies.

Taking NCEPU as an example, this paper investigates and analyzes the time preference of the students in the major categories of enrollment, the factors that affect the professional choice, and then analyzes the advantages and disadvantages of the shunt mode, and puts forward a set of complete triage mode implementation rules.

\section{Questionnaire Research}

\subsection{Research Method}

In this investigation, various factors were taken into consideration. Only a part of colleges and universities were selected as samples to conduct research, including the North China Electric Power University where the author is located. ${ }^{[1]}$ In the design of the questionnaire, the author formed a prediction questionnaire by consulting relevant documents, browsing information online, and listening to suggestions through random interviews. ${ }^{[2]}$ Afterwards, the 2017 grade students enrolled in the large-scale enrollment at the North China University of Electric Power were randomly selected to fill in the questionnaire, and based on the results of the answer and feedback from the feedback students, the overall construction of the questionnaire, item description, layout layout Made appropriate revisions and adjustments to form a formal questionnaire "thinking and exploring about the diversion model under the major types of enrollment policy."

\subsection{Result Analysis}

A total of 375 e-questionnaires were sent out and 350 questionnaires were returned. The recovery rate was $93.33 \%$, of which 315 were valid and the effective rate was $84 \%$. As shown in Table 1 , the research objects are mainly concentrated in the third grade and the other grades are distributed.

\subsection{Time Selection of Professional Diversion}

Choosing the right time for the diversion is a key part of the implementation of the major enrollment policy, and it is crucial for students to learn general knowledge and professional courses as well as the future development of each major. ${ }^{[3]} 71.06 \%$ of the students expressed that they hoped to be able to transfer to their favorite professional learning during the sophomore year, and $22.86 \%$ of the students expressed that they would like to have a professional diversion at the end of the first year, with only a few Some of the students chose to perform professional diversion in the junior year, accounting for 6.35\%.Premature professional diversion will lead students to not pay enough attention to and deepen the study of general education courses, and fail to achieve the purpose of running a "thick foundation and wide caliber" for large-scale recruitment, losing its original meaning. Late professional diversions are likely to weaken students' learning of professional knowledge, affect student employment choices, and the strengths and weaknesses of each major. Regardless of from which perspective, completing the relevant work of professional diversion in the second year of the sophomore year is relatively reasonable and scientific. It is not only the expectation of the students, but also the first choice for universities and professional colleges.

Factors affecting professional diversion. Professional selection determines the career development direction of an individual to a certain extent, and is crucial to the development of life. In recent years, with the increasing demand for complex and innovative talents in society, the large-scale recruitment model has emerged in many talent reform practices. It provides students with an in-depth understanding of the school's academic status, professional strengths, curriculum matching, and a self-examination buffer period, giving students a greater choice of professional choice, which will help students make more reasonable professional choices. ${ }^{[4]}$ The author sorted out 12 influencing factors through survey questionnaires. According to the characteristics of common factors among them, they can be classified as employment prospects, personal characteristics, influence of others, and professional strength. Use the "importance index" to analyze the degree of influence of various factors on professional diversion. ${ }^{[5]}$ The greater the importance index, the greater the influence of this factor on students' professionalism; on the 
contrary, the smaller the index. In the questionnaire, the degree of importance is divided into three levels and assigned: 1 means not important, 2 means normal, and 3 means important. The "importance index" is calculated as:

$$
\eta=\sum_{i=1}^{3} a_{i} * x_{i} / 3
$$

It represents the weighting coefficient of the $\mathrm{i}$ th grade among the three different degrees of importance. When $\mathrm{i}=1,2$, and 3, it is equal to 1,2 and 3 , respectively; it means that the number of people who choose the $i$ th grade is the percentage of the effective respondent of the project. The statistical results in Table 4 show that among all the influencing factors, the importance index of "personal characteristics" and "employment prospects" is similar and largest, and it is the main factor affecting professional diversion, followed by "professional strength" and "impact of others". It can be seen that, when the subject of a student chooses professional choice, either his or her own interest and personal ability are emphasized, and professional employment prospects and subject strength are also emphasized. The "advice and choice of others", a factor that has a greater influence on student professional selection in the traditional professional enrollment model, has proven to have less impact on student major selection in the major enrollment model. This shows that under the background of major enrollment, the advantages of professional diversion in colleges and universities promote students' rational choice of majors.

Table 1 Importance Index Analysis of Multifactors (\%)

\begin{tabular}{|c|c|c|c|c|c|c|}
\hline category & Project Description & 1 & 2 & 3 & $\eta$ & Average $\eta$ \\
\hline \multirow{5}{*}{$\begin{array}{c}\text { employment } \\
\text { prospect }\end{array}$} & Wide range of employment & 8.5 & 26.8 & 64.7 & 85.4 & \multirow{5}{*}{86.3} \\
\hline & Employment remuneration & 6.5 & 15.5 & 78.0 & 90.5 & \\
\hline & employment rate & 5.5 & 16.5 & 78.0 & 90.8 & \\
\hline & $\begin{array}{l}\text { Employment and social } \\
\text { status }\end{array}$ & 17.2 & 20.5 & 62.3 & 81.7 & \\
\hline & Employment area & 15.5 & 20.3 & 64.2 & 82.9 & \\
\hline \multirow{3}{*}{$\begin{array}{c}\text { Personal } \\
\text { characteristic } \\
\text { s }\end{array}$} & personal interest & 8.5 & 10.5 & 81.0 & 90.8 & \multirow{3}{*}{87.8} \\
\hline & Personal ability and specialty & 10.2 & 21.2 & 68.6 & 86.1 & \\
\hline & $\begin{array}{c}\text { Personal personality } \\
\text { matching }\end{array}$ & 10.5 & 19.5 & 70.0 & 86.5 & \\
\hline \multirow{2}{*}{$\begin{array}{l}\text { Influence } \\
\text { others }\end{array}$} & Others' suggestions & 15.5 & 23.5 & 61.0 & 81.8 & \multirow{2}{*}{78.3} \\
\hline & The choice of others & 22.5 & 30.5 & 47.0 & 74.8 & \\
\hline \multirow{2}{*}{$\begin{array}{l}\text { Professional } \\
\text { Strength }\end{array}$} & Professional influence & 9.5 & 14.5 & 76.0 & 88.8 & \multirow{2}{*}{85.2} \\
\hline & Professional teacher & 15.5 & 24.5 & 60.0 & 81.5 & \\
\hline
\end{tabular}

\section{Detailed Rules for the Implementation of Major Categories of Enrollment and Diversion}

On the basis of sorting out and studying the rules of diversion under the general enrollment policy promulgated by North China Electric Power University, and on the basis of fully analyzing the merits and demerits of the distributary mode, we propose a set of distributary rules suitable for North China Electric Power University with distinctive specialties. The flow of shunt is shown in Figure 1.

After previous research, we found that for colleges and universities that have a clear target for service in the future and focus on specialized fields and industries, the reason for most candidates to apply for the college is for the so-called "hot major" in the school, that is, the strong subject. Even if they fail to be assigned to a strong subject in the in the college entrance examinations, most students express that they would like to be assigned to the major through a secondary volunteer assignment. At the same time, due to the "wrong" guidance of parents and senior students based on the employment prospects, it is unscientific to emphasize the interest-oriented diversion schemes in such colleges and universities. In view of this phenomenon, we combine the characteristics of North China Electric Power University with its distinctive power characteristics, a set of relatively 
scientific segregation rules (limited to professional selection within departments) has been developed.

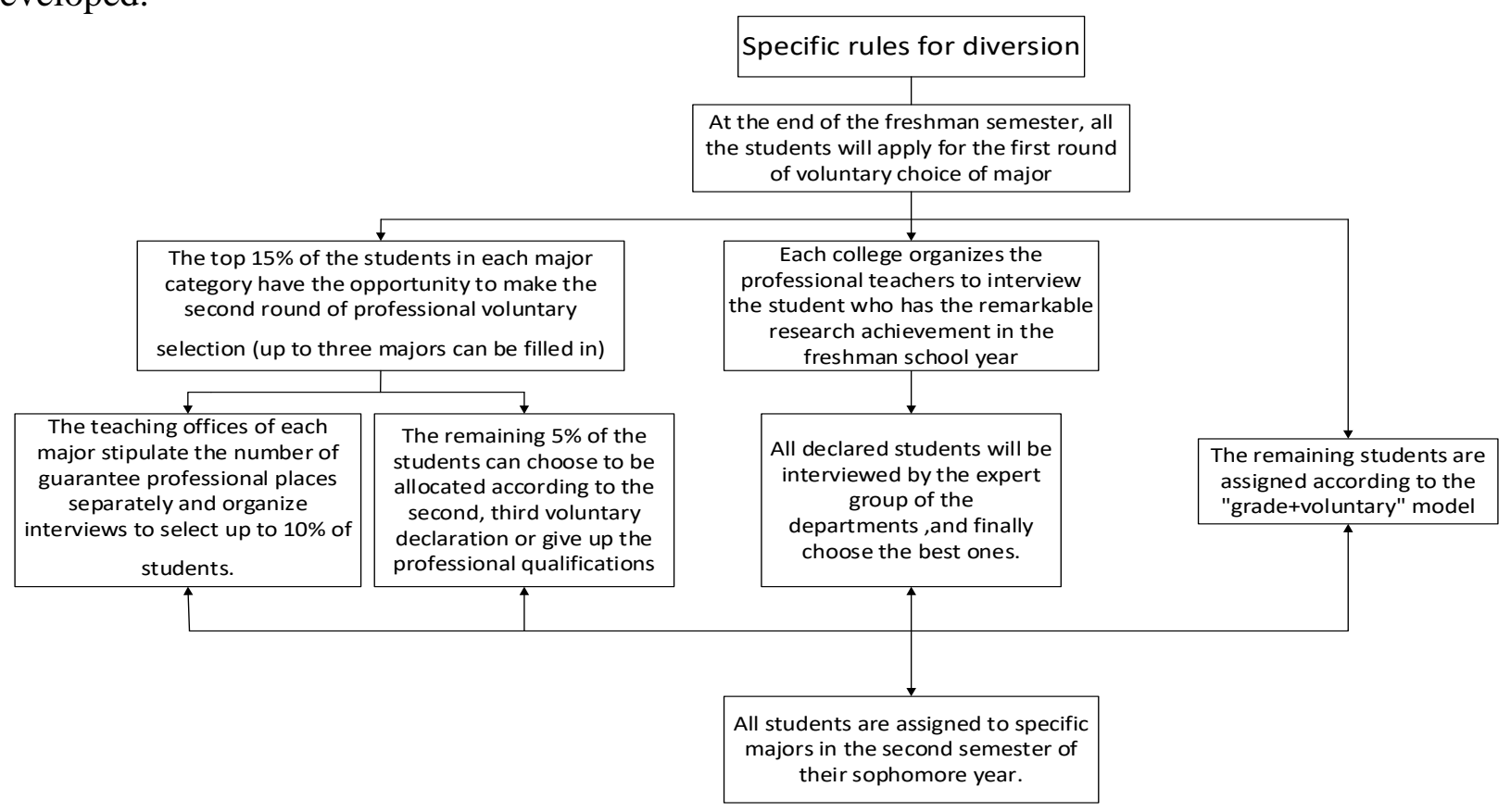

Fig. 1 The flow of shunt

(1) In the next semester of freshman year, all the students fill in the voluntary choice of major, and the responsible persons of each college sort out the students' selection results. Based on the results of the selection, they conduct a systematic analysis to get a preliminary understanding of the students' preferences for different categories of majors. At the same time, according to the results of the research, each department formulates the relevant professional courses, and reports the results of the course selection to the Academic Affairs Office, which arranges the integration of the courses and offers special courses for each major in the sophomore semester. This kind of elective course is regarded as the required credit in addition to the basic compulsory course of sophomore students. Students can choose any two elective courses according to the previous major, and this kind of course is recorded in the grade statistics of the sophomore year.

(2) In September of the first semester of sophomore year, the relevant departments of each college counted the results of all general education courses in freshman year. The top $15 \%$ of the students in each major category have the opportunity to make the second round of professional voluntary selection (up to three majors can be filled in), each department organizes students to interview according to the result of the selection, and the examiner is composed of teachers of different majors in each department. Before the interview, the teaching offices of each major stipulate the number of guarantee professional places separately and used them as a restriction for admission of students. If the number of students who choose the so-called hot major is large, then the teachers of that major will screen some students for admission based on the results of the interview. The remaining students may choose to accept the second or third volunteer transfers (provided that the second and third volunteers are not fully enrolled and the professional teacher approves them) or to give up the qualification of the profession in advance, students who give up the qualification should participate in the "grade+voluntary" model assignment after the end of the sophomore semester. Finally, according to the grades and the results of the interview determined that $10 \%$ of the students in the department (the specific proportion can be adjusted by the department of their own) to obtain professional qualifications.

(3) In addition to academic performance, students in the freshman academic year may complete high-level scientific research achievements such as papers or competitions independently or in teams, and all students with such achievements are eligible to obtain professional qualifications in advance. The students also conduct interviews with the same period of the above-mentioned rules (2). The interviewer may ask questions about the relevant problems of the specific scientific 
research results, and then score the students' performance and the level of the scientific research achievements, and finally, according to the results of the interview, the students with significant scientific research results have the opportunity to obtain professional qualifications in advance.

(4) After the end of the sophomore semester, in addition to those students who have obtained the professional qualifications in advance, the remaining students fill in the second round of professional voluntary selection (up to three majors can be declared) in the first semester of their sophomore year, and such students are assigned from high to low on the basis of their full course scores in the freshman and sophomore years (including elective courses for different majors chosen by each classmate in the sophomore year), If the number of the first volunteer is full, the second and third volunteer arrangements will be accepted in sequence, and if the three volunteers are fully filled, they need to be transferred, and the final results of the diversion of all students can be announced through the educational administration website during the sophomore winter vacation.

Only students with a credit score of $5 \%$ in each major category and significant scientific research results (related to the major content chosen by the student) in the freshman academic year are eligible to make professional choices throughout the school. This kind of students must accept the relevant interview in September of the sophomore semester. The result of the interview is decided by the interview group teachers of the specific major of the student's choice, and the selection process is the same as the above-mentioned diversion rules (2) and (3).

\section{Conclusion}

The cultivation of talents is the essential requirement and the basic mission of higher education, with the rapid development of socialist economy and the constant reform of higher education, the demand of compound and innovative talents is urgent, which promotes the establishment and perfection of new talents training mode. In many talent training mode, according to the discipline of the mode of admission to the major categories with its unique advantages stands out, gradually for the universities to adopt. It is an important step to improve the students ' general education level in order to transform the University into the comprehensive university, and to carry out the major class enrollment diversion training.

Because the characteristic university has the strong specialized superiority characteristic, in carries on the diversion rule design should notice the student to the superiority specialized preference causes the shunt voluntary excessively centralism, after the shunt student whole management question solves. As a high school with electric power characteristics, NCEPU should strengthen the management of the students majoring in the education of the non-electric majors, enlarge the construction of the curriculum, improve the overall teacher education level, optimize the training mode of shunting talents, and establish a sound evaluation system for the quality of personnel training, to ensure the continuous improvement of the triage mechanism.

\section{References}

[1] Wang Zuojun, Liuqin, Niu Zhonghui, Wang Xiaokang, Wang Caihong. The influential factors of students ' professional choice under the mode of large-class training [J]. Journal of Ningbo University (Education Science Edition), 2014,36 (03): 8-13. (In Chinese)

[2] Tan SuQiong. Analysis on the pros and cons of large-class enrollment in colleges and universities [J]. China higher Education Research, 2009 (1): 88-89. (In Chinese)

[3] Wu Minglong. Statistical analysis and application statistics of SPSS statistics [M]. Beijing: Science Press, 2013:109. (In Chinese)

[4] Shi Hanyu, Wei Zhuo, etc. A study on students ' professional choice under large enrollment in universities [J]. Technology information, 2009 (25): 134-134. (In Chinese)

[5] Zhong Yuping. Lu Genshu. Analysis on the influencing factors of students ' choice of University under the charging conditions [J]. Higher Education Studies, 1999 (2): 31-37. (In 


\section{Chinese)}

[6] Wang Zuojun, Liu Qin. The influential factors of students ' professional choice in the major class enrollment mode [J]. Journal of Ningbo University, 2015. (In Chinese) 